\title{
COMENTÁRIOS DO DIREITO INTERNACIONAL MODERNO: EXISTÊNCIA, BUSCA PELA UNIVERSALIDADE E A ESCOLHA DA IGUALDADE FORMAL ENTRE ESTADOS E POVOS
}

\author{
COMMENTARIES OF THE MODERN INTERNATIONAL LAW: EXISTENCE, SEARCH FOR \\ UNIVERSALITY AND THE CHOICE OF FORMAL EQUALITY BETWEEN STATES AND PEOPLE
}

Aline Almeida Coutinho Souza*
Aline Schraier de Quadros**

Resumo:

Neste estudo apresentamos reflexões de temas referentes ao Direito Internacional Público no tempo moderno, período compreendido entre a Paz de Westphalia (1648) e o Concerto Europeu (1815). Sabendo que ao estudioso do direito internacional é essencial o conhecimento de sua história para melhor compreensão, decidimos, para tanto, nos debruçar sobre a contextualização histórica e política, que culminou no colapso do poder temporal e no advento da modernidade. Seguiremos com discussões referentes à existência e ao conteúdo do direito internacional e também pela busca da universalidade. E, ao final, apresentamos considerações sobre o princípio da igualdade entre Estados.

Palavras-chave: Estado. Direito Internacional. Direito Natural. Igualdade. Universalidade.

\begin{abstract}
:
In this essay we present reflections on subjects related to Public International Law in the Modern Period, from the Peace of Westphalia (1648) to the Concert of Europe (1815). Knowing that, in order for the International Law scholars to have a better understanding on this topic, it is essential the knowledge of its history. We focused on the historical and political contexts that culminated in the collapse of the temporal power and the advent of modernity, followed by discussions regarding the existence and content of international law and the quest for universality. In the ending part of the essay, we presented the principle of equality among the States.
\end{abstract}

Keywords: State. International Law. Natural Law. Equality. Universality.

\footnotetext{
Advogada; doutoranda em direito internacional e comparado pela Universidade de São Paulo, sob orientação do Prof. Dr. Geraldo Miniuci Ferreira Junior; e mestre em direito internacional público e europeu pela Universidade de Coimbra, sob orientação do Prof. Dr. Jónatas Machado.

** Advogada, mestranda em direito do comércio internacional pela Universidade de São Paulo, sob orientação da Prof ${ }^{a}$. Dra. Maristela Basso.
} 
Introdução

Neste artigo buscamos apresentar comentários pertinentes acerca do Direito Internacional Público compreendido no lapso temporal de 1648 a 1815, Tratado de Westphalia e Concerto Europeu - respectivamente. Período este usualmente chamado de modelo clássico ou modelo de Westphalia do direito internacional. Algumas observações preliminares são necessárias, afinal não é nossa intenção esgotar todo o tema referente ao direito internacional no período moderno, pois perseguir tal tarefa hercúlea seria atitude inapropriada nestas poucas páginas. Assim que uma seleção de temas a serem apresentados se mostrou não apenas inelutável, como necessária.

O primeiro ponto a estudarmos será: a contextualização histórica e política que levou a termo a guerra religiosa dos Trinta Anos e possibilitou o surgimento do Estado moderno. Indubitavelmente a denominação de "modelo clássico" ou "modelo de Westphalia" é resultado de uma construção doutrinária feita a partir das narrativas vencedoras europeias, portanto artificiosa e falível porque reduz a realidade em que estava inserida. Feita esta nossa observação, devemos esclarecer que mesmo assim podemos identificar grandes tendências e princípios estruturantes fundamentais (ALMEIDA, 2003, p. 30).

Depois da contextualização, partimos à apresentação do conteúdo do Direito Internacional, cujas discussões referentes à sua fundamentação, acreditamos que recaiam sobre a distinção entre direito internacional e direito natural, além de qual seria seu âmbito de abrangência e aplicação de cada um desses. Ainda exporemos doutrinadores que pregam o radical entendimento da negação deste próprio instituto.

Adiante veremos a busca pela universalidade, a qual se deu em muito em decorrência das transformações inegáveis ocorridas entre os séculos XVII e XIX. Vislumbramos que o aperfeiçoamento da vida internacional, fez com que o mundo não se visse mais como um aglomerado de países isolados, fechados em si mesmos. Sendo que a partir desta nova realidade, ilustrada pela interdependência, criou a necessidade de haver um Direito com aplicação universal, que englobasse a todos os Estados.

Por fim, abordaremos a escolha pelo princípio da igualdade formal entre os Estados adotado e incorporado pelo Tratado de Westphalia ao ordenamento jurídico internacional. A sociedade internacional dessa época era formada por uma vasta planície de Estados, desiguais materialmente, que optam pela abstração jurídica da igualdade formal a fim de cooperar em prol da paz. Ressalta-se que, mesmo que teoricamente esses Estados estejam situados num mesmo plano paritário, isso não significa que havia de fato tratamento igualitário entre seus atores no contexto internacional. Ponto que inclusive atualmente ainda não alcançamos (DUPUY, 1993, p. 31). 
O estudo do desenvolvimento histórico do Direito Internacional se mostra imprescindível se quisermos compreendê-lo melhor atualmente, afinal é fruto das características da sociedade internacional de cada época, sendo de fato, um ramo do Direito essencialmente evolutivo. Dito isso passamos à análise do tema.

\section{1. $\mathrm{O}$ caminho à modernidade}

A Idade Moderna é um período específico da História do Ocidente que se estende do final do século XV até a Idade das Revoluções no século XVIII. Os limites cronológicos são objeto de debate, mas convenciona-se assinalar o seu início em 1453, com a tomada de Constantinopla pelos turcos otomanos, e a data do seu término com a Revolução Francesa, em 1789.

Esse período histórico inclui, pois, o Renascimento, a Reforma Protestante (a Bíblia de Gutenberg - 1460; Martin Lutero - 1517; Guerras dos 30 anos que se inicia em 1618) e a Era dos Descobrimentos (Colombo - 1492; Vasco da Gama - 1500; Fernão de Magalhães - 1522 e Dinastia Ming - XVI). Esses três movimentos históricos, nos campos da cultura, religião e comércio que, além de interagirem entre si, também se influenciaram mutuamente, resultando no desenho do contexto no qual estavam imersos os pensadores e líderes que conceberam a Paz de Westphalia, em 1648.

Ademais, o século XVI caracteriza-se pela destruição da supremacia do papado pelo movimento da Reforma Protestante. A quebra da unicidade do mundo cristão fortaleceu os Estados nacionais, ambiente que Jean Bodin eternizou com a sua formulação da noção clássica de soberania: "The sovereign has supreme power over citizens and is not bound by any laws". Essa definição favoreceu o absolutismo como o tipo de governo que prevaleceu neste período (ALMEIDA, 2003, p. 217).

Foi também nessa época que houve a chamada 'primeira globalização', com os grandes descobrimentos, institucionalização do comércio internacional regular entre Europa, América, Ásia e África. Cabe ressaltar que o continente europeu apresenta algumas características geográficas que permitiram que os acontecimentos da Idade Moderna tomassem forma e se desenvolvessem.

Especialmente no que dizrespeito ao comércio, a Europa é toda interconectada por grande malha fluvial navegável que permite o transporte de mercadorias em toda a sua extensão. Ainda, a Europa está situada em um ponto estratégico de comunicação com o mundo todo o que viabilizou, e viabiliza até hoje as rotas de comércio, cultura e ideias tanto com o "mundo árabe" e o "mundo asiático". E depois uma vez dominados os meios de navegação, com a África e Américas (MARSHALL, 2015, p. 336).

O fluxo de novas ideias do Renascimento, o embate das concepções religiosas na Reforma Protestante, e o florescimento do comércio, geraram na Europa 
crescentes tensões, desconfortos e conflitos de interesses que desencadearam guerras cruéis e avassaladoras.

Em resposta ao ambiente desarmônico que se institui no contexto da Idade Moderna, na Europa, para encerrar a guerra dos 30 anos, foi assinado o Tratado de Westphalia. Os termos desse documento foram negociados por três anos nas cidades de Münster e Osnabrück e, os tratados concluídos nestas duas cidades foram reunidos no Ato Geral de Westphalia. Tratava-se de uma 'ordem criada por Estados para os Estados' que, pela primeira vez, tinham deliberado em conjunto. Este instrumento revela-se importantíssimo para o desenvolvimento na evolução histórico-política e também jurídicointernacional, servindo de base ao designado Ius Publicum Europaeum (ACCIOLY, 2012, p. 90-91).

De acordo com Jónatas Machado (2013, p. 75-76), sua importância reside fundamentalmente:

1. Na afirmação da centralidade da figura do tratado internacional na conformação das relações entre os Estados;

2. Os Estados agora com poderes soberanos absolutos em seu território, atuavam tanto no domínio político quanto no religioso, sem interferências do Papa;

3. Introduz o princípio da tolerância religiosa, dando razão a Grócio que afirmava que as relações de dependência recíprocas se estabelecem com a garantia de tolerância religiosa e respeito pelo direito internacional;

4. Alcançar a solução politica-jurídica para os conflitos lançou base para a secularização da política, do Estado, do direito interno e internacional, a partir de princípios de direito natural racionais;

5. Por último, mas não menos importante, foi a criação do Estado Suíço, a independência dos países-baixos da Holanda e também a anexação da Alsácia à França.

Com o modelo de Westphalia, houve um significativo fortalecimento da França na cena internacional, com sucessivas guerras contra a Espanha, Suécia, Inglaterra e Estados germânicos. Esse período compreendido de 1648 até 1815 ficou conhecido como Época francesa (MACHADO, 2013, p. 79-82) afirmando o francês como a língua da diplomacia.

O Tratado de Utrecht, que acabou com a guerra de sucessão espanhola e, um pouco depois, em 1763, o Tratado de Paris, que colocou fim a Guerra dos Sete Anos, são documentos que reafirmaram o princípio de equilíbrio de poderes, mencionado em Westphalia, como regulador das relações entre Estados soberanos e absolutistas.

O absolutismo monárquico dominava a constituição dos Estados europeus o que era um foco de resistência constante à afirmação do direito internacional, mesmo assim surgiram autores que procuravam aprofundar as ideias trazidas por Grócio como Zouch, Pufendorf, Wolff, von Martens e Vattel. 
Destacamos que esse contexto favoreceu o desenvolvimento do domínio do Direito Internacional denominado de "lex mercatoria". Trata-se de um arcabouço de usos, costumes, princípios mercantis, regras, códigos de conduta, procedimentos arbitrais de resolução de disputas, com previsão de reconhecimento de personalidade jurídica e do direito de propriedade aos estrangeiros.

Por fim, no direito da guerra, é interessante mencionar que houve também grandes repercussões dessa época histórica. Por exemplo, houve a delegação real do direito de declarar a guerra nas companhias majestáticas ultramarinas, no caso de violação de direitos territoriais, de igual forma é que estas companhias de capitais privadas, criadas por carta real, reclamavam para si o direito de imunidade soberana (MACHADO, 2013, p. 82).

Compreender o contexto histórico em que se desenvolveu o Direito Internacional clássico permite observar com maior clareza como os institutos fundadores foram desenvolvidos. Permitindo assim compreender como esses institutos se adaptaram para incorporar o arcabouço jurídico internacional da atualidade.

\section{Discussões acerca do conteúdo do Direito Internacional}

Como vimos em tópico anterior, ainda na Idade Média o direito internacional era alicerçado no ideal regulativo que pôde ser designado por "consenso da cristandade", em que o jusnaturalismo católico era dominante. Esse modelo perdurou até a Reforma e às guerras religiosas e, desde então a emergência do direito internacional moderno corresponde fundamentalmente à superação dessa metateoria à sua substituição por um ideal regulativo secularizado, de matriz jusnaturalista racionalista, ou seja, que fosse válido mesmo para o caso de Deus não existir ${ }^{1}$ (GRÓCIO, 2001, p. 10). Podemos ver a secularização progressiva do direito internacional em Alberico Gentili, mas é principalmente em Hugo Grócio que ela se desenvolve (MACHADO, 2013, p. 77).

Hugo Grócio considerado por grande parte da doutrina o pai do direito internacional, estuda a realidade da vida internacional sob um ponto de vista laico, separando-o de seus antecessores. Defendia a liberdade dos mares, das comunicações e do comércio, o que ia contra as pretensões dos Estados soberanos. Ademais em sua obra de Jure Belli ac Pacis distingue o direito natural do direito voluntário: o natural seriam as normas transcendentes que os Estados devem respeitar, podendo inclusive os seus súditos extrair de uma ordem injusta, um direito de resistência à opressão e; o voluntário seria o Direito positivo, que deriva dos costumes e dos tratados (SHAW, 2003, p. 12).

Trecho original: “(...) the Law of Nature is so unalterable, that it cannot be changed even by God himself. For although the power of God is infinite, yet there are some things, to which it does not extend". 
A partir de Grócio podemos traçar duas escolas, de um lado temos os naturalistas, como Pufendorf, que identificava o direito internacional com o direito natural. Esta escola via o direito natural como um sistema moral e assim negava validade não apenas dos costumes, mas também das normas convencionais. De outro lado temos os positivistas, como Zouch e Bynkershoek, os quais expressavam a importância de problemas práticos dos Estados, este pensamento deriva do método empírico adotado pelo Renascimento, cuja preocupação não restava na estruturação de teorias, mas em discutir questões atuais (SHAW, 2003, p. 24-25).

Ademais é possível vermos no trabalho de Vettel, elementos tanto da escola positivista quanto da naturalista. Este doutrinador baseava-se em princípios naturais, contudo era orientado pela prática empírica. Apresentou ainda a doutrina da igualdade dos Estados perante o direito internacional, asseverando que um pequeno país não poderia ser preterido mesmo se comparado ao maior reino² (ACCIOLY, 2012, p. 52).

Aparentemente a escola positivista parecia ter relegado o direito natural à história, no entanto ele ressurgiu repaginado, com o conceito de direitos naturais, numa afirmação da supremacia individualista. Advindo principalmente da ideia dos contratualistas, um acordo entre indivíduos, que buscava justificar a sociedade civil, cuja ênfase recaía sempre no papel central do indivíduo, não importando se a teoria contratual tinha uma visão mais pessimista, que exigia um soberano absoluto, como Hobbes, ou mais otimista como Locke. Foi uma doutrina inovadora que alicerçou as Revoluções Francesa e Americana e a própria essência da democracia moderna. Não obstante essa mesma doutrina apresentava também pontos retrógrados utilizados para preservar a soberania, argumentando que o que era, deveria assim ser, em decorrência do próprio contrato social ou, inclusive ordenado divinamente. Neste ponto Malcom Shaw assevera que o raciocínio utilizado para manutenção do poder dependerá do quão secular a sociedade em questão entende por direito natural (SHAW, 2003, p. 25; MACHADO, 2013, p. 78-79). Mas então como poderíamos definir o conteúdo do direito internacional?

Sabemos que ele é formado pelos Estados que não estão subordinados a nenhuma autoridade de sobreposição, ou seja, não reconhecem nenhuma autoridade acima deles. Neste cenário os Estados unem-se numa base voluntária e são soberanos na avaliação de seu próprio direito. Isto quer dizer que a norma internacional nem sempre é compreendida do mesmo modo por todos e que, tendo os Estados a tendência de personalizar seus interesses, a paz pode de fato ser precária. E é por isso que se combate

Trecho original: “(...) é da maior importância para as nações que o direito das gentes (...) seja respeitado universalmente. Se alguma nação espezinhar abertamente esse direito, todas podem e devem insurgir-se contra ela, e ao reunirem suas forças, para punir esse inimigo em comum, elas estão cumprindo com seus deveres, para consigo mesmas e para com a sociedade humana, da qual são membros”. 
tanto a noção de soberania, pois é o maior obstáculo à primazia do direito internacional. Contudo não podemos nos esquecer que a soberania é uma noção histórica e a história não se altera rapidamente utilizando apenas argumentos lógicos, é preciso firmar os acontecimentos de hoje com tamanha força que o normal de ontem se torne discutível amanhã.

Acreditamos que esse processo de transformação tenha se iniciado após as 2 grandes guerras mundiais que bem demonstraram o que pode ocorrer com soberanias desmoderadas, com o surgimento das organizações internacionais, como a Liga das Nações e logo depois com a Organização das Nações Unidas (DUPUY, 1993, p. 5-8). Fato é que atualmente não temos uma definição que seja aceita por toda a doutrina, inclusive há ainda questionamentos se tal definição seria de fato necessária, na medida em que o direito internacional possui tamanha dinamicidade que defini-lo seria em verdade limitálo (MACHADO, 2013, p. 23).

Dito isso partimos agora à análise dos debates acerca da existência do direito internacional.

\subsection{Existência $\mathrm{x}$ Negadores}

Como sabemos, o tempo moderno viu o nascer do Estado absolutista monárquico que dominava a constituição dos Estados europeus e esta soberania absoluta era um grande foco de resistência à afirmação de um direito internacional. Tamanho que houve teóricos proeminentes que puseram a existência do direito internacional em causa. Importa ressaltarmos que muito embora esse debate seja histórico ele ainda não foi esquecido, porém nos parece um tanto desarrazoado pretender rejeitar por completo a existência do direito internacional pós-moderno, afinal não há como negar que ele tenha se desenvolvido e se institucionalizado.

Então por entendermos que esse debate surpreendentemente ainda existe atualmente é que nos parece útil reportar aqui os principais negadores e suas razões. Dr. Casella (2014, p. 57-67) em sua doutrina apresenta que a negação do direito internacional se dava sob vários aspectos, como o seu conceito, existência, liberdade e independência dos povos, dentre outros. Mas aqui reportaremos os 2 grandes grupos de negadores, os práticos e os teóricos. Vejamos:

\section{Negadores práticos:}

Negam a existência do direito internacional e de qualquer norma que regulamente a vida internacional. Formado por Espinosa, Lasson, Gumplowicz e Lundsedt, estes doutrinadores alegam a inexistência do direito internacional em razão de não haver um sistema normativo coercitivo que seja superior ao Estado soberano e, por 
isso não teria como garantir a obrigatoriedade dos tratados e, que estes não teriam valor se dispusessem de matérias que opusessem de seus interesses particulares ou que alterassem a relação de forças entre os Estados (MELLO, 1997, p. 87-98).

\section{Negadores teóricos:}

Estes por sua vez reconhecem a existência de normas internacionais, mas negam sua natureza jurídica. Citamos aqui Austin e Binder, que dizem que as normas internacionais são simples regras morais, sendo aplicadas como cortesia pelos Estados, em razão de uma prática constante (MELLO, 1997, p. 98).

Mas poderiam proceder essas críticas à existência do direito internacional? Os negadores práticos, a nosso ver não distinguem o "ser" do "dever ser", no sentido de que ao verem abusos sendo cometidos internacionalmente, chegam à conclusão de que os Estados não seriam então submetidos a essas regras. E, de fato à primeira vista poderíamos ter a impressão de que há só violência e rescisões de tratados e convenções na vida internacional, no entanto importante ter em mente que essas violações são a minoria, se comparadas com a intensidade da vida internacional. Não obstante é verdade que a repercussão dessas violações seja ampla, afinal acarretam grandes impactos. Mesmo assim seria completamente despropositado querer dizer que não há nenhuma norma que limite as condutas dos Estados, ora se isso fosse verdade resultaria numa vida internacional completamente anárquica - com soberania absoluta e impossibilidade de organização. Onde as relações internacionais seriam praticamente impossíveis, como paz e cooperação, transportes, comércio internacional, comunicação e o sistema financeiro. O que não corresponde com a atualidade, pois temos organismos internacionais que condicionam este poder (DUPUY, 1993, p. 125; MELLO, 1997, p. 99).

Já acerca dos negadores teóricos, entendemos que eles comparam o direito internacional com o direito nacional o que de fato fica fadado ao fracasso. Afinal o direito internacional é fenômeno recente se comparado com o direito interno. Mas mesmo assim não podemos considerar as normas internacionais simplesmente como regras morais, porque é possível aplicarmos sanções às violações internacionais, temos para isso a Corte Internacional de Justiça, os Tribunais regionais de proteção aos direitos humanos (como a Corte Europeia, a Corte Interamericana e a Corte Africana) e inclusive o Tribunal Penal Internacional. Agora se as sanções aplicadas não são as esperadas, isso não quer dizer que não possuem natureza jurídica, mas sim que atuam com eficácia aquém da desejada - afinal é extremamente difícil organizar uma sanção coercitiva, porque se fundamenta na restrição da arbitrariedade dos Estados (MELLO, 1997, p. 100).

Além dos negadores apresentados supra, temos outros que não negam a existência do direito internacional, mas o consideram como um Direito imperfeito, seja pela falta de uma comunidade internacional, pela falta de uma organização central para 
impor sanções, ou ainda pelas normas internacionais serem consideradas obscuras, porque uma declaração de guerra faria cessar o Estado de Direito entre os Estados. Dentro deste grupo podemos citar Savigny, Wilson e Zitelmann. Mas novamente podemos rechaçar esta teoria utilizando o fato destes doutrinadores estarem pretendendo limitar a ciência jurídica internacional pela visão apresentada no direito estatal do Estado moderno, cuja soberania absoluta deixava a sociedade internacional em estado de anarquia. No entanto, quando o direito passa a ser promulgado e não outorgado, o poder estatal fica limitado, dando suporte ao direito internacional institucionalizar-se (MELLO, 1997, p. 101).

Como dissemos no início deste capítulo, esses pensamentos não são exclusivamente históricos, pois a questão da qualidade jurídica do direito internacional sucede com todos aqueles que hoje se mostram desiludidos com sua aparente incapacidade de evitar as atrocidades cometidas nas relações entre Estados. Mas apesar das fragilidades, não podemos pensar que o direito internacional é inoperante, afinal ele existe e é efetivamente levado em consideração no seio da comunidade internacional, correspondendo à interação internacional legitimada. O que não significa dizer que é impecável e insuperável, o direito internacional ainda é fragmentado e ambíguo, entretanto, apesar dos pesares, tem logrado desenvolvimentos muito significativos desde então (MACHADO, 2013, p. 24; TRINDADE, 2010, p. 2).

\section{A busca pela universalidade}

O direito internacional moderno como vimos acima, não surge do nada e tampouco pode ser compreendido sem o estudo de suas raízes medievais e antigas, afinal o seu desenrolar histórico é vital para o seu entendimento como disciplina autônoma, como ocorreu com o direito natural, ele já havia sido adotado e incorporado pelos romanos no seu jus gentium. E foi este jus gentium, enriquecido pela adição do direito natural, o responsável pela construção de um ideal de direito universal, aplicável a todas as relações entre humanos. Assim essa lei foi aplicada aos principados em suas relações recíprocas e acabou se tornando o direito comum, ou seja, o direito romano (CASELLA, 2014, p. 7273; BRITO, 2008, p. 15-16).

O triunfo do cristianismo seria um ponto de partida para a concepção de direito universal dos homens e também ao desenvolvimento das relações diplomáticas como elemento estruturante da política internacional e seus efeitos se projetaram aos tempos seguintes (CASELLA, 2014, p. 74). ${ }^{3}$ Quando houve a ruptura da unicidade

LE FUR, 1927 apud CASELLA, 2014, p. 74, trecho: “(...) não quer dizer que a obra de construção política da Idade Média tenha sido perfeita; não existe obra humana que o seja, mas ela foi muito superior a todas as do passado - e mesmo algumas do futuro - sobretudo como construção do conjunto". 
religiosa, as relações entre os Estados, que foram ficando cada vez mais independentes, era um fator que não poderia ser mais negado e um novo período foi inaugurado. Como o período das descobertas, um continente inteiro que antes não se tinham notícia, se torna objeto de trânsito regular de navios com pessoas, ideias, escravos, especiarias, ouro e prata, madeira, carnes, peles, vinhos e etc., acarretando no processo da primeira globalização dominada pela expansão mercantilista.

Essas transformações mostram mutação irreversível e radical do quadro do mundo. Vitória e Suarez perceberam e afirmaram a intrínseca unidade fundamental do gênero humano, bem como a necessidade da correspondente adaptação das estruturas jurídicas destinadas a regular a convivência entre as sociedades humanas, aprofundandose em problemas circunstanciados de moralidade que se coloca à consciência humana e ao governo dos povos. Designando as relações entre as nações (ius inter gentes), com um elemento natural e outro positivo (CASELLA, 2014, p. 81). É onde aparece a semente do princípio da cooperação universal e coordenação pacífica entre os diferentes Estados (CASELLA, 2014, p. 82).

O direito das gentes se aplica então a mais ampla comunidade de nações, ideia bastante distante daquele direito que antes era voltado estritamente ao bem-estar dos Estados. As normas já não podem ser livremente editadas, modificadas ou suprimidas, mesmo que por decisão de autoridade que presida cada uma das comunidades que compõem os sujeitos do direito internacional, antecipando as normas cogentes, que foram adotadas mais tarde pela Convenção de Viena de 1969. O direito então começa a se impor segundo o interesse comum da humanidade (CASELLA, 2014, p. 82-83).

$\mathrm{O}$ aperfeiçoamento da vida internacional corresponde ao estágio mais avançado da evolução, com as convenções internacionais e até as criações das organizações internacionais (sejam elas de vocação universal ou regional). Essa arquitetura de civitas maxima busca manter o direito internacional enraizado no direito natural, preocupandose com as necessidades permanentes e razoáveis da natureza do homem e da natureza das coisas, como ensina Wolff (TRINDADE, 2010, p. 28; CASELLA, 2014, p. 83). Assim para este autor, o direito internacional seria resultado da vontade da comunidade internacional e não dos Estados individualmente considerados.

Pelo que podemos perceber, o direito internacional clássico experimentou expansão considerável e inegável de seu ramo de atuação, afinal ela acompanha os avanços da sociedade. No entanto foi apenas na segunda metade do século XX, após duas grandes guerras mundiais e incontáveis vidas perdidas, que de fato vemos a inclinação do direito ao universalismo, desvencilhando-se daquela estrita visão estadocêntrica, colocando enfim o direito acima da raison d'État. Com o aumento da participação dos indivíduos na vida internacional, ao lado das organizações internacionais e Estados, podemos dizer que atualmente o direito internacional interessa a todos. Afinal neste novo jus gentium, 
há grande preocupação com temas que antes eram marginalizados da pauta internacional, desde a proteção do meio ambiente, até a proteção de mulheres e crianças e de minorias étnicas. Dessa forma nos alinhamos ao doutrinador e juiz internacional Cançado Trindade, quando diz que estamos caminhando a uma nova mudança, saindo da retrógrada raison d'Etat para a vanguardista raison d'humanité (TRINDADE, 2010, p. 51).

4. Escolha da igualdade formal entre estados e povos

O princípio da igualdade entre os Estados, noção fundamental tanto para o Direito Internacional quanto para a organização da sociedade como um todo, abrange um sistema de igualdade soberana de Estados que compõem uma forma de organizar competências e exercício de poder na sociedade internacional.

Trata-se da isonomia normativa em que as regras internacionais são produzidas e destinadas imparcialmente para todos os Estados, como unidades autônomas e formalmente iguais.

Estamos aqui diante do paradigma da coexistência, em que a lógica do bilateralismo, coordenação e sociedade relacional em que o Direito Internacional era moldado exclusivamente por e para Estados. Em contraposição ao paradigma da cooperação em que as relações internacionais se desenvolveram após a $2^{\mathrm{a}}$ Guerra Mundial (GIANNATTASIO, 2016, p. 60).

A Paz de Westphalia introduz a igualdade como princípios fundamentais das relações internacionais, e desde então esse princípio basilar do corpo normativo do Direito Internacional estando presente na Carta das Nações Unidas, na Carta de Direitos e Deveres Econômicos dos Estados, na Declaração Relativa aos Princípios do Direito Internacional Referentes às Relações de Amizade e à Cooperação entre Estados conforme a Carta das Nações Unidas (A/RES/25/2625), além de um grande número de tratados, convenções, resoluções e demais instrumentos da ordem jurídica internacional.

Para Pufendorf, o fundamento material do direito natural repousa na liberdade, igualdade e sociabilidade dos homens. A liberdade origina-se da dignidade natural e, em razão desta, é igual em todos, fazendo com que, juridicamente, por direito natural, todos os homens sejam iguais. A igualdade de todos é o fundamento do direito natural.

Esse princípio, para cuja formulação contribui Grócio, Pufendorf, Wolff, Vattel e muitos outros (CASELLA, 2014, p. 70), hoje faz parte da nossa compreensão de Direito Internacional. Mas, cabe ressaltar, foram muitos os estudos realizados - dentro do contexto histórico anteriormente apresentado - que buscavam justificar a desigualdade entre os estados e critério que poderiam ser invocados para a defesa da "dignidade" e 
"precedência" de determinado estado em detrimento de outro na ordenação do sistema internacional de convivência da época.

E, se aceita a premissa da desigualdade, de uma diferença de desigualdade entre os estados, vinha à tona, então a discussão dos critérios para a determinação da precedência entre príncipes e estados (CASELLA, 2014, p. 620-626).

A escolha por adotar o princípio da igualdade em detrimento dessas teorizações representou um salto evolutivo significativo para o sistema internacional. Foi uma resposta para as crescentes e complexas tensões daquele dado momento histórico da Europa, que não encontrariam, é bem possível vislumbrar, qualquer solução caso tivessem prevalecido as ideias de dignidade e precedência.

Pode-se verificar que o Direito Internacional não são meras regras, mas um processo de decisões políticas. José Carlos de Magalhães traz o alerta de Myres S. McDougal para que "o Direito Internacional seja encarado não como simples regras, mas, como todo um processo de decisões amparadas por autoridades na esfera mundial" (MAGALHÃES, 2017, p. 24).

Ressalte-se que igualdade jurídica e formal entre os Estados, não exclui a realidade da desigualdade de fato econômica e militar, justamente geradora de todas essas tensões e conflitos infindáveis.

\section{Considerações Finais}

Pelo que foi apresentado supra, procuramos fornecer uma visão, ainda que sucinta, do desenvolvimento histórico do direito internacional especificamente no tempo moderno. Esta retomada no tempo demonstra o quão importante é o estudo formativo desta temática, afinal pelo que podemos perceber muitos dos temas políticos, jurídicos, econômicos e religiosos tratados neste artigo, mostram-se hoje surpreendentemente atuais. De tal modo que referências ao passado são essenciais para que possamos compreender o nosso presente.

O direito internacional desenvolve-se em função das evoluções das sociedades em que está inserido, ora vimos que com a constituição dos Estados modernos, grande preocupação restava em preservar a soberania absoluta e a concentração de poder. Contudo já sabemos que a anarquia internacional traz como consequência a precariedade da norma, afinal cada Estado a interpretaria de forma mais conveniente para si. De forma que a guerra era uma solução normal para as animosidades, o Tratado de Westphalia que pôs a termo a guerra dos 30 anos, não foi de forma alguma o único tratado cuja temática central era cessar ou afastar conflitos armados. A paz era absolutamente precária e havia necessidade de ordem, como ocorre em qualquer comunidade. 
Observamos então os ensinamentos trazidos pelos grandes estudiosos do direito internacional, que presenciando aquela realidade, buscavam alternativas não com o objetivo de alterá-la, mas reinventá-la. Propunham a supremacia do direito entre as gentes ao raison d'État, a cooperação universal e coordenação pacífica, a igualdade dos povos e Estados e a liberdade dos mares. Apesar disso, a interdependência buscada não correspondia, infelizmente com as consciências que ainda mantinham-se fortemente nacionalistas e, quando não conseguiram chegar a comum acordo, duas grandes guerras eclodiram.

Sem embargo, o que já se havia postulado ainda na idade moderna, não foi esquecido. Pelas transformações ocorridas num mundo que havia assistido a duas guerras mundiais, estava cristalino que mudanças deveriam ser feitas e foi ali, que de fato vimos a inclinação do Direito ao universalismo, desvencilhando-se daquela estrita visão estadocêntrica, colocando enfim o Direito acima da raison d'État e possibilitando uma maior participação dos indivíduos na vida internacional, ao lado das organizações internacionais e Estados.

Nessa transformação radical, vimos o nascer das organizações internacionais que buscam não apenas condicionar o poder dos Estados, como também repreendê-lo. Chegando a decretar a proibição geral da guerra, da ameaça ou do uso da força e inclusive a institucionalizar a jurisdição internacional. Mas sabemos que mesmo após essas significativas mudanças, hábitos antigos ainda persistem e conflitos armados violentíssimos continuam fazendo parte da nossa realidade. Muito embora ainda tenhamos um longo caminho a ser percorrido para que cheguemos ao raison d'humanité, é importante que tenhamos em perspectiva o quanto que já foi alcançado.

Curitiba, abril de 2019.

\section{Referências}

ACCIOLY, Hildebrando Pompeo Pinto; SILVA, Geraldo Eulálio do Nascimento e; CASELLA, Paulo Borba. Manual de direito internacional público. 20. ed. São Paulo: Saraiva, 2012.

ALMEIDA, Francisco Ferreira de. Direito internacional público. 2. ed. Coimbra: Coimbra Ed., 2003.

BRITO, WLADIMIR. Direito internacional. Coimbra: Coimbra Ed., 2008.

CASELLA, Paulo Borba. Direito internacional no tempo moderno de Suarez a Grócio. São Paulo: Atlas, 2014.

DUPUY, René-Jean. O Direito internacional. Coimbra: Almedina 1993. 
GIANNATTASIO, Arthur Roberto Capella. União Europeia: o direito político da Comunidade Europeia do Carvão e do Aço. Curitiba: Juruá, 2016.

GROTIUS, Hugo. On the law of war and peace. Tradução de A. C. Campbell. Kitchener: Batoche Books, 2001.

MACHADO, Jónatas Eduardo Mendes. Direito internacional: do paradigma clássico ao pós-11 de setembro. 4. ed. Coimbra: Coimbra Ed., 2013.

MAGALHÃES, José Carlos de. Direito econômico internacional: tendências e perspectivas. 2. ed. rev. e atual. Curitiba: Juruá, 2017.

MARSHALL, Tim. Prisoners of geography: ten maps that tell you everything you need to know about global politics. London: Elliott \& Thompson, 2015.

MELLO, Celso D. de Albuquerque. Curso de direito internacional público. 11. ed., rev. e aum. Rio de Janeiro: Renovar, 1997. v. 1.

SHAW, Malcolm Nathan. International law. 5. ed. Cambridge: Cambridge University Press, 2003.

TRINDADE, Antônio Augusto Cançado. International law for humankind: towards a new jus gentium. The Hague: Martinus Nijhoff, 2010. 